\title{
Hidroelektrik ve Termik Santrallerin Karbon Emisyonu Üzerindeki Etkilerinin Araştırılması: Eskişehir İli Örneği
}

\author{
Yıldırım BAYAZIT* \\ Bilecik Şeyh Edebali Üniversitesi, Inşaat Mühendisliği Bölümü, Bilecik \\ (ORCID: 0000-0002-8699-4741)
}

\begin{abstract}
$\ddot{O} z$
Dünya nüfusunun hızla artmasıyla birlikte gelişen sanayi ve teknolojik gelişmeler ihtiyaç duyulan enerjiyi de arttırmaktadır. İhtiyaç duyulan enerjinin en önemlilerinden bir tanesi elektrik enerjisidir. Günümüzde elektrik enerjisi ihtiyacının büyük bir bölümü fosil kaynaklardan sağlanmaktadır. Elektrik enerjisinin fosil kaynaklardan sağlanmasının iklim değişikliği ve çevre kirliliği problemlerine yol açtığı bilinen bir gerçektir. Bu nedenle enerji üretiminde yenilenebilir enerji kaynaklarının kullanılması konusu tüm dünyada büyük önem kazanmıştır. Ülkemizde hidroelektrik enerji santrallerin yanı sıra sulama, içme-kullanma suyu temini ve taşkın gibi amaçlarla işletilen birçok baraj bulunmaktadır. Bu çalışmada, enerji üretiminde su kaynaklarından daha efektif bir şekilde yararlanmak için kurulu barajların enerji üretebilme olanakları değerlendirilerek termik santrallere göre daha çevreci bir çözüm yaklaşımı hedeflenmiştir. Bu bağlamda çalışmada Eskişehir ilindeki Porsuk Barajının hidroelektrik enerji santraline dönüştürülmesi durumunda enerji üretimi ve karbon emisyon azaltımı SIMAHPP 5 programı kullanılarak hesaplanmıştır. Sonuç olarak Porsuk Barajının 4.31 MW’lık kurulu güçle yıllık 597 GWh enerji üretebileceği hesaplanmıştır. Aynı enerji miktarının termik santrallerden üretilmesi durumunda yılda ortalama 5,5631.55 $\mathrm{tCO}_{2}$ karbon salınımı yapabileceği ortaya konmuştur.
\end{abstract}

Anahtar kelimeler: Tükenebilir Enerji, Yenilenebilir Enerji, Termik Santral, Hidroelektrik, Karbon Emisyonu.

\section{Investigation of the Effects of Hydroelectric and Thermal Power Plants on Carbon Emission: Example of Eskişehir Province}

\begin{abstract}
With the rapid increase in the world population, developing industry and technological developments also increase the energy needed. One of the most important energies needed is electrical energy. Today, most of the electrical energy needs are provided by fossil sources. It is a known fact that obtaining electrical energy from fossil sources causes climate change and environmental pollution problems. For this reason, the issue of using renewable energy sources in energy production has gained great importance all over the world. In our country, besides hydroelectric power plants, there are many dams operated for irrigation, drinking-potable water supply and flooding purposes. In this study, a more environmentally friendly solution approach than thermal power plants is aimed by evaluating the energy generation possibilities of installed dams in order to benefit from water resources more effectively in energy production. In this context, energy production and carbon emission reduction in the case of converting the Porsuk Dam in Eskişehir to a hydroelectric power plant was calculated using the SIMAHPP 5 program. As a result, it has been calculated that the Porsuk Dam can generate $597 \mathrm{GWh}$ of energy annually with an installed power of 4.31 MW. It has been demonstrated that if the same amount of energy is generated from thermal power plants, an average of $5.5631 .55 \mathrm{tCO} 2$ of carbon emission per year can be achieved.
\end{abstract}

Keywords: Consumable Energy, Renewable Energy, Thermal Power Plant, Hydroelectricity, Carbon Emission.

\section{Giriş}

Hizla artan dünya nüfusuyla birlikte gelişen endüstrinin getirdiği sonuçlardan bir tanesi ihtiyaç duyulan enerjinin artmasıdır. Günümüzde küresel enerji talebinin \%87 gibi çok büyük bir bölümü petrol,

*Sorumlu yazar: yildirim.bayazit@ bilecik.edu.tr
Geliş Tarihi: 17.02.2020, Kabul Tarihi: 01.04.2021 
doğalgaz ve kömür tarafından karşılanmaktadır [1]. Teknolojinin bugünkü düzeyi ve yapılan tahminler doğrultusunda gelecek 20 ylllık sürede de toplam dünya enerji talebinin \% 88'inin fosil yakitlar tarafından karşılanmaya devam edeceği tahmin edilmektedir [2]. Ancak fosil kaynakların tükenebilir olması, çevreyi kirletmesi son yıllarda yenilenebilir temiz enerji kaynaklarının önemini ortaya çıkarmıştır. Yenilenebilir enerji kaynakları (hidrolik, jeotermal, güneş, rüzgâr, biyokütle, dalga vb.), ülkelerin enerji politikaları içinde yerli kaynak olmaları, enerji arz güvenliğine katkı yapmaları, temiz olmaları, küresel ısınma ile mücadelede salınımları azaltmaları, çevresel kaygıların giderilmesinde katkı sağlamaları ve Kyoto Protokolü mekanizmaları kapsamında ekonomik değer taşıma özellikleri nedeniyle büyük öneme sahiptir. Yenilenebilir enerji kaynaklarının düşük karbon ekonomisine geçme amacıyla kullanımı, dünya genelinde her geçen gün daha da yaygınlaşmaktadır. Özellikle kömür ve petrol türevi enerji santrallerinin ihtiyaç duyulan enerjiyi karşılaması sırasında ortaya çıkardıkları karbondioksit gazı atmosferde birikerek iklim üzerinde olumsuz etkiler yapmaktadır. Bu durum küresel iklim değişikliğine neden olmaktadır.

Elektrik güç santralleri kullanılan kaynağa göre termik, hidrolik ve nükleer elektrik santralleri olarak sınıflandırılmaktadır. Bu çalışmada termik ve hidrolik enerji santralleri ele alınacaktır.

\subsection{Termik santrallerin karbon emisyonu üzerindeki etkileri}

Termik santraller, genel prensip olarak 1sı enerjisini elektrik enerjisine dönüştüren santrallerdir. Termik santrallerin en bilinen tipi yakıt olarak kömür ham maddesini kullanan santrallerdir. Bu enerji santrallerinde öncelikle yakıtta bulunan kimyasal enerjiyi kazanda 1s1 enerjisine çevirerek buhar elde edilir. Daha sonra buhardaki isı enerjisi türbin yardımıyla mekanik enerjiye çevrildikten sonra jeneratörde elektrik enerjisine çevrilir. Termik santrallerin çalışma prensibi şematik olarak Şekil 1'de verilmiştir. Kömür santralleri dünyada elektrik enerjisi üretiminde en çok faydalanılan santrallerdir. Dünya elektrik enerjisi üretiminin yaklaşık \%38'i kömür rezervlerinden sağlanmaktadır (WCA, 2020). Termik santraller çevreye zararlı birçok gaz verirken, termal kirlilik olarak bilinen bir çevre problemini ortaya çıkarır. Termal kirlilik, atık suyun elektrik santralinden deşarjı ile yerel çevredeki doğal kaynakların kirlenmesine neden olur. Çevrede bulunan yeraltı ve yerüstü su kaynakları bu durumdan olumsuz etkilenirler. Termik santrallerin emisyonlarıyla ilgili son yıllarda birçok çalışma yapılmıştır. Liu vd. [3] Güney Afrika' da bulunan bir kömür termik santralinden atmosfere salınan sera gazını uydu görüntülerinden faydalanarak analiz etmişlerdir. Gai vd. [4] termik santrallerin karbon emisyonları için tipik bir hesaplama analizi ortaya koymuşlardır. Termik santrallerin çevreye duyarlılığını arttırmak için $\mathrm{CO}_{2}$ salınımını azaltma teknolojileri üzerine 2012 yılında Moazzem vd. bir çalışma yayınlamışlardır [5].

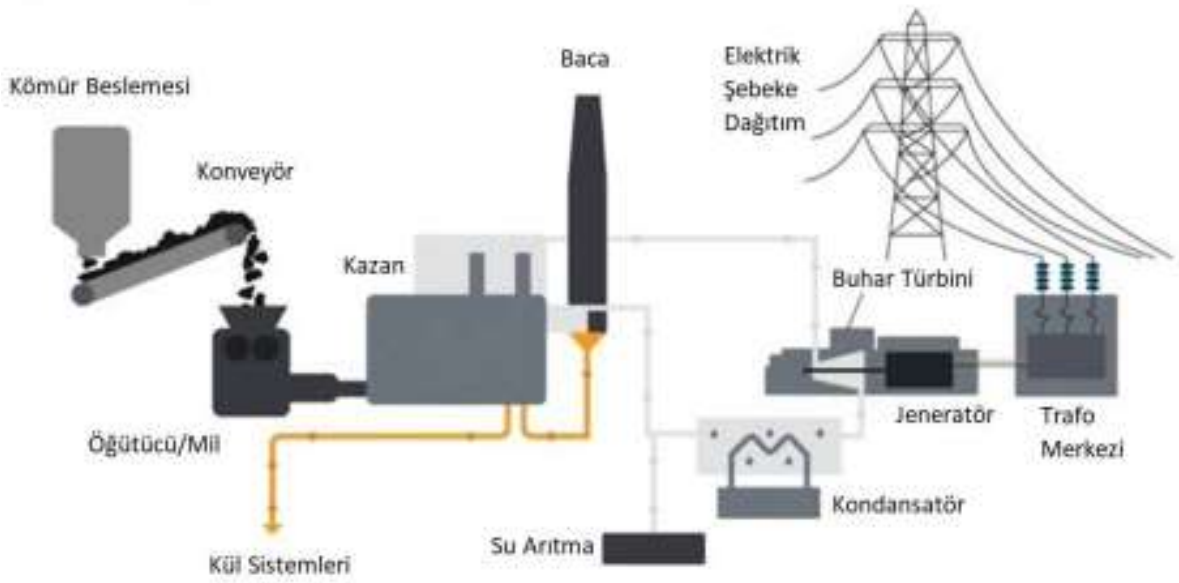

Şekil 1. Bir termik santralin çalışma prensibi [6]

Termik santrallerin fosil yakıtları atmosfere yakmanın yan ürünü olan çok sayıda sera gazı ve kül pompaladığı bilinmektedir. Bu durum insan sağlığı üzerinde birçok problemleri ortaya çıardığ1 bilinmektedir [7]. Termal santrallerden atmosfere salınan gazlardan en önemlileri karbondioksit, kükürt dioksit ve azot oksitlerdir.

Karbondioksit $\left(\mathrm{CO}_{2}\right)$, fosil yakıtların yakılmasından çıkan ana gazlardan biridir. Sera gazının, küresel iklim değişikliğinin en büyük sorumlularından biri olduğu bilinmektedir. Özellikle kömür yakıtlı 
santraller enerji üretiminde $\mathrm{CO}_{2}$ emisyonlarının \%34-40'ını oluşturarak küresel olarak en büyük antropojenik $\mathrm{CO}_{2}$ yayıcıları arasında yer aldıkları bilinmektedir [8]. Bir termik santralden salınan tüm gazlardan en önemlisi karbondioksit olup, termik santraller tüm dünyada artan karbondioksit seviyelerine en çok katkıda bulunan enerji üretim tesisleridir. Dünya kömür rezervlerinin önümüzdeki on yıllar boyunca enerji üretiminde kullanımı devam edeceği düşünüldüğünde $\mathrm{CO}_{2}$ emisyonlarının ana sebebi olmaya devam edecektir [9]. Bu nedenle, iklim değişikliğini daha iyi tahmin etmek için enerji üretiminde küresel $\mathrm{CO}_{2}$ emisyonlarının doğru bir şekilde izlenmesi ve etkili emisyon azaltma stratejilerinin geliştirilmesini desteklemek önemlidir [9].

Kükürt dioksit, enerji santrallerinden salınan bir diğer gazdır. Teknik olarak bir sera gazı olmamakla birlikte, atmosfere dolaylı etkilerinin olduğu bilinmektedir. Çünkü gelen güneş ışığının saçılmasını, bulutların oluşumunu ve yağış modellerini etkileyebilir. Bu nedenle, birçok durumda dolaylı bir sera gazı olarak kabul edilir. Sülfür dioksit atmosferde sülfürik asit oluşturur, daha sonra Dünya'ya asit yağmuru olarak dönebilir ve çeşitli ekosistemleri etkileyebilir. Termik santrallerden salınan kükürt dioksit seviyesi kullanılan kömürdeki kükürt miktarına bağlıdır. Kullanılan kömürün hangi tipte kullanıldığına bağlı olarak ortalama \% 0.1 ila \%3.5 kükürt vardır. Termik santraller aynı zamanda dünya çapında en büyük kükürt dioksit yayıcılarıdır.

Azot oksitler, termik santraller tarafindan atmosfere salınan bir başka gaz grubudur. Termik santraller küresel azot oksit seviyelerine en büyük katkıda bulunanlardan biridir. Karbondioksitlerden farklı olarak, azot oksitler yine teknik olarak sera gazları değildir, ancak atmosfer üzerinde dolaylı bir etkiye sahiptirler. Azot oksitlerin görünürlük ve solunum sorunları yarattığı bilinmektedir ve ayrıca asit yağmuru ve duman oluşturmak için diğer atmosfer gazları ve nem ile birleşebilirler.

Atmosferin bir diğer büyük kirleticisi küldür. Kül genellikle zararlı partikül maddeler ve ağır metaller içerir. Külün birden fazla etkisi olabilir; düştügü her yerde su yollarına ve toprağa girebilir (yerel çevre olması gerekmez). Bu durum toprağın veya suyun alkalinitesini değiştirerek toprağı tarımsal amaçlarla kullanılamaz hale getirebilir. Ayrıca su içilmez hale gelebilir.

\subsection{Hidroelektrik enerjinin karbon emisyonu üzerindeki etkileri}

Hidrolik enerji, yenilenebilir enerji kaynakları içerisinde teknolojik gelişim açısından en ileri düzeyde olan enerji kaynăğdır. Suyun potansiyel enerjisinin kinetik enerjiye dönüştürülmesiyle elde edilen bu enerji türü, yenilenebilir enerji kaynakları arasında en büyük paya sahiptir (Şekil 2). Hidroelektrik enerji düşük karbon emisyonlu bir teknoloji olarak, dünyanın yenilenebilir enerji üretiminin yaklaşık üçte ikisini karşılamaktadır.

Hidroelektrik santrallerinin oluşturdukları az miktardaki sera gazı emisyonları rezervuarlarındaki su bitkileri ve alg biokütlelerinin ürettiği organik maddelerin ayrışması sonucu oluşmaktadır. Termik santrallerde ise sera gazı salınımının en önemli nedenlerinden biri fosil kaynağın yakılması işlemidir. Yanma işlemi atmosfere büyük miktarda $\mathrm{CO}_{2}$ salınımı yaptığından, termik santrallerin hidroelektrik enerji santrallerine göre kıyaslanmayacak kadar büyük miktarlarda karbon salınımı meydana getirdiği bilinmektedir.

Hidroelektrik enerji projeleri, Paris Anlaşması ve sürdürülebilir kalkınma hedefleri çerçevesinde ülkelere iklim değişikliğinin olumsuz etkilerinden (taşkın ve kuraklık) korunmasını sağlar. Hidroelektrik enerji diğer enerji kaynaklarıyla kıyaslandığında kilovat saat başına en düşük sera gazı (GHG)(GreenHouseGases) salınımına sahip olduğu bilinmektedir. Bir kömür santralinin ortalama yaşam döngüsü karbon eşdeğeri yoğunluğu $820 \mathrm{gCO} 2-\mathrm{eq} / \mathrm{kWh}$ iken bir hidroelektrik santralin 18.5 $\mathrm{gCO} 2-\mathrm{eq} / \mathrm{kWh}$ olduğu söylenmektedir. Bu durum hidroelektrik santrallerin kömür santrallerine göre \%97.7 oranında sera gazı emisyonunu azalttığını göstermektedir. Hidroelektrik enerji kilovat saat başına doğalgaza göre $\% 96.2$, biokütleye göre $\% 92$, solar PV'ye göre $\% 61.5$, jeotermale göre $\% 51.3$ sera gaz1 emisyonunu azaltmaktadır. Rüzgâr enerjisi ise hidroelektriğe göre sera gazı salınımında $4 \% 0.5$ oranında avantaj sağlamaktadır. Tüm bu değerler göz önüne alındığında eşdeğer bir enerji üretiminde bir hidroelektrik santralin yerine kömür santrali kullanıldığında atmosfere yılda 4 milyar ton fazladan sera gazı salınımı olacağı tahmin edilmektedir. Enerji üretiminde kömür gibi bir fosil yakıta göre sudan faydalanmak atmosfere bırakılan 148 milyon ton partikül, 62 milyon ton sülfür dioksit ve 8 milyon ton nitrojen oksitin de önüne geçmek anlamına gelmektedir. 


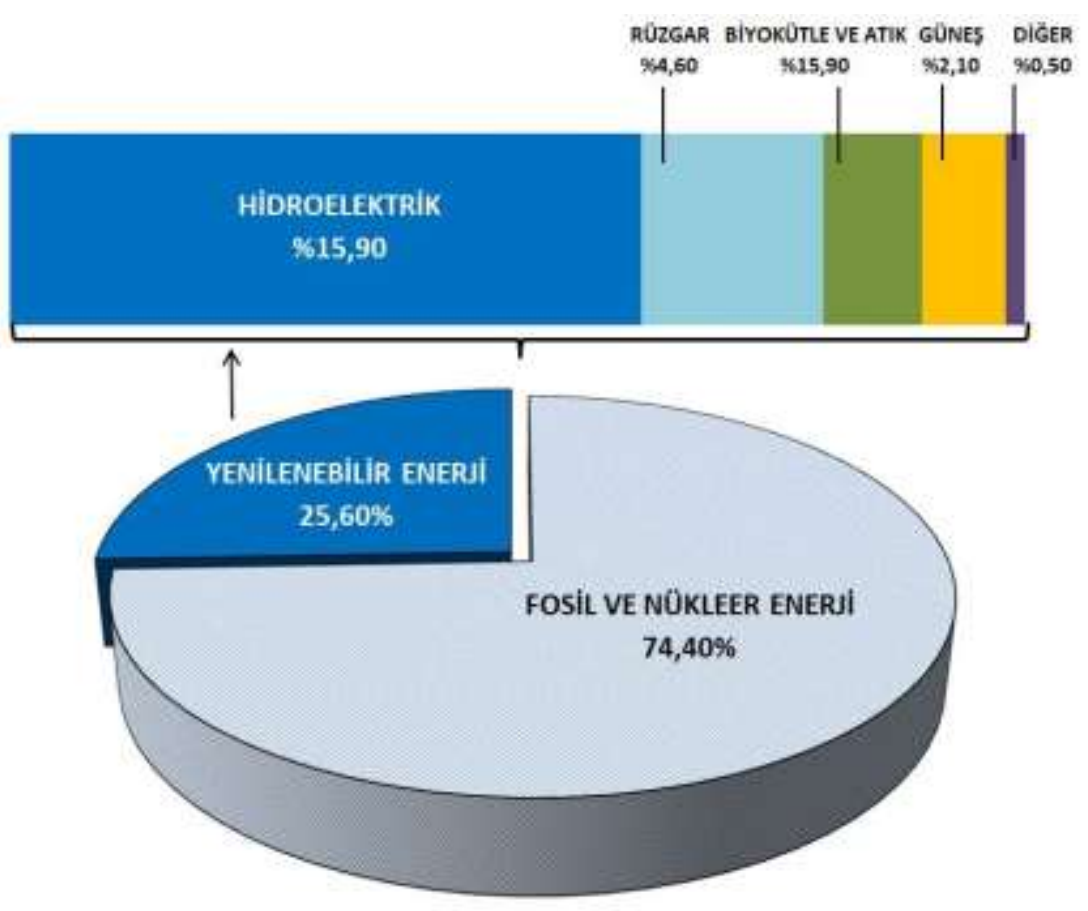

Şekil 2. Yenilenebilir enerjide hidroelektriğin rolü [10]

\section{Materyal ve Metot}

Çalışmada kullanılan verileri üç ana başlık altında toplamak mümkündür. Bunlardan ilki hidrolojik verilerdir. Hidrolojik veriler bölgeye ait akarsulardaki akım gözlem istasyonlarından elde edilen debi değerleridir. Bu veriler Eskişehir'de bulunan Devlet Su İşleri 3. Bölge Müdürlügü’nden elde edilmiştir. Çalışmada kullanılan bir diğer veri tipi ise çalışma bölgesindeki elektrik santrallerine ait enerji ve karbon salınımları verileridir. Bu veriler Türkiye İstatistik Kurumu ve T.C. Enerji ve Tabi Kaynaklar Bakanlığı verilerinden elde edilmiştir. Ayrıca çalışma alanı olarak seçilen Eskişehir bölgesinde konumsal analizlerin yapılabilmesi için bölgeye ait sayısal haritalar Harita Genel Komutanlığı'ndan elde edilmiştir.

\section{1. Çalışma Alanı}

Hidroelektrik ve termik enerji santrallerinin karbon salınımına etkisini ortaya koymak için inceleme bölgesi olarak Eskişehir ili seçilmiştir (Şekil 3). Eskişehir, Türkiye'nin İç Anadolu Bölgesinde bulunan 2020 yılı itibariyle 887,475 nüfusa sahip bir şehridir. Şehirde sanayi son yıllarda oldukça gelişmiştir. $\mathrm{Bu}$ durum bölgenin elektrik enerjisine olan ihtiyacın da son yıllarda sanayi ve nüfustaki gelişmeyle birlikte doğru orantılı olarak artmaktadır.

Eskişehir'de toplam 17 adet elektrik enerji santrali bulunmaktadır (Tablo 1). Bunlardan 1'i biyogaz, 2'si hidroelektrik, 3'ü termik ve doğalgaz, 8'i ise güneş enerji santrallerinden oluşmaktadır [11]. Bu santrallerin konumları ve il sınırlarındaki kurulu güç dağılımları Şekil 4.a'da gösterilmiştir. Bu santrallerin il genelinde toplam $558 \mathrm{MW}$ kurulu gücü bulunmaktadır. Toplam kurulu gücün \%54.61'ini yenilenebilir enerji kaynakları oluştururken \%45.39'unu yenilenemeyen enerji kaynakları oluşturmaktadır. Bu santraller atmosfere yılda ortalama $1 \mathrm{GWh}$ başına toplam 215 ton $\mathrm{CO}_{2}$ sera gazı salınımı yapmaktadır. Santrallerin il sınırları genelindeki dağılımları Şekil 4.b’de gösterilmiştir. 


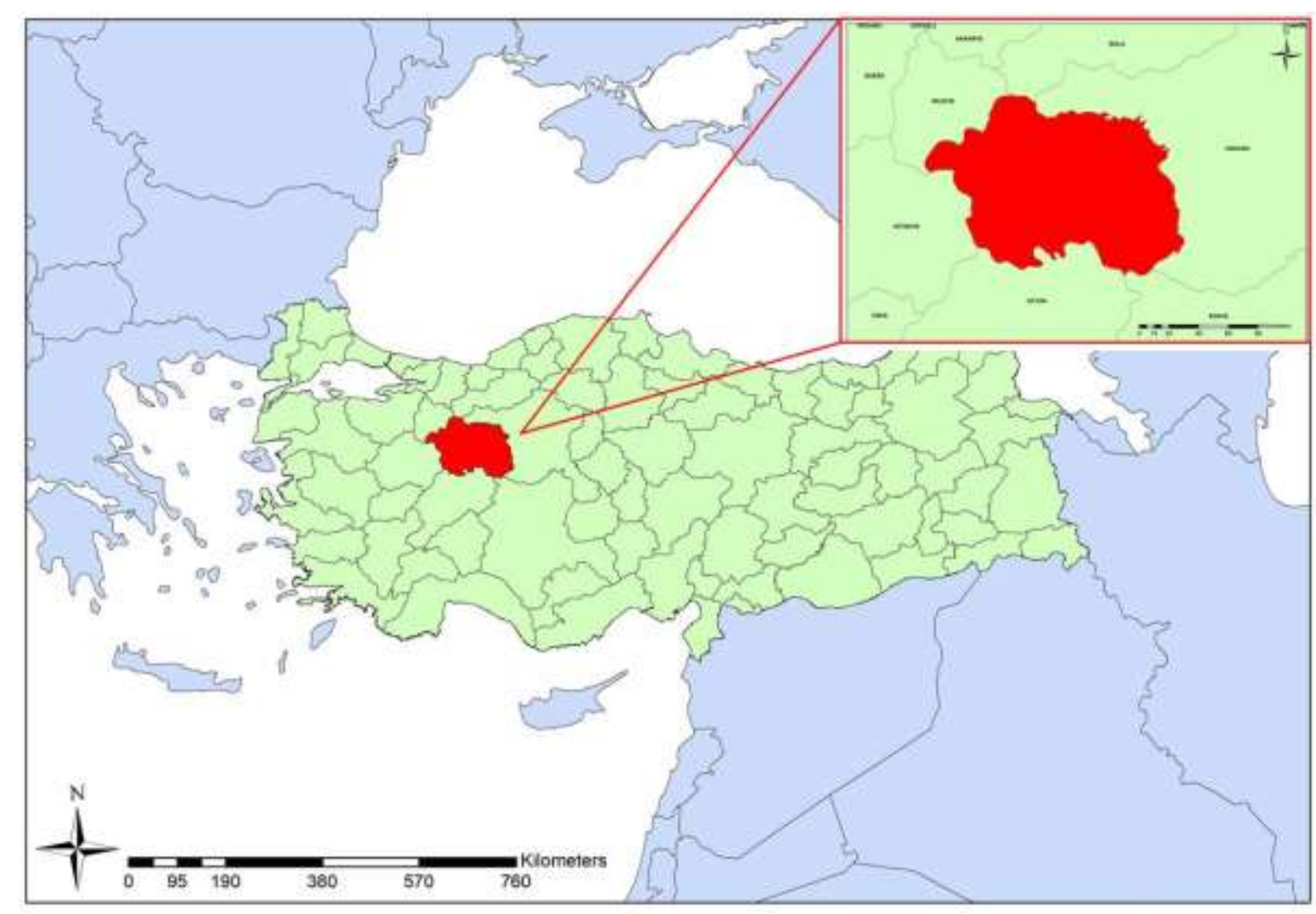

Şekil 3. Çalışma alanın konumu

Tablo 1. Eskişehir ilindeki elektrik enerjisi üreten santraller [11]

\begin{tabular}{|c|c|c|c|c|}
\hline \multicolumn{2}{|c|}{ Koordinat } & \multirow{2}{*}{ Santral İsmi } & \multirow{2}{*}{$\begin{array}{l}\text { Kurulu Güç } \\
\text { (MW) }\end{array}$} & \multirow{2}{*}{$\begin{array}{c}\text { Ortalama Sera Gazı Salınımı } \\
\left(\mathrm{tCO}_{2}\right)\end{array}$} \\
\hline $\mathbf{x}(\mathbf{m})$ & $\mathbf{y}(\mathbf{m})$ & & & \\
\hline 330771 & 4433315 & Gökçekaya HES & 278 & 6.394 \\
\hline 383372 & 4426858 & Yunus Emre Termik Santrali & 145 & 152.830 \\
\hline 296630 & 4402909 & $\begin{array}{c}\text { Eskişehir OSB Termik } \\
\text { Santrali }\end{array}$ & 59 & 29.441 \\
\hline 286633 & 4351880 & Kırka Bor Termik Santrali & 18 & 11.088 \\
\hline 310267 & 4438842 & Beyköy HES & 17 & 0.442 \\
\hline 289148 & 4406011 & $\begin{array}{l}\text { Şeker Fabrikası Doğalgaz } \\
\text { Santrali }\end{array}$ & 16 & 7.984 \\
\hline 261989 & 4411097 & İnönü Kojenerasyon Tesisi & 6.92 & 3.453 \\
\hline 295988 & 4402213 & "Doğalgaz Santrali & 6.31 & 3.149 \\
\hline 282487 & 4402522 & "Biyogaz Santrali & 2.04 & 0.053 \\
\hline 356207 & 4372053 & Çayören GES & 2 & 0.046 \\
\hline 355494 & 4372105 & "GES1 & 2 & 0.046 \\
\hline 260651 & 4401020 & "GES2 & 1.82 & 0.042 \\
\hline 398038 & 4359835 & Günyüzü GES & 1.76 & 0.041 \\
\hline 360473 & 4370539 & Söğütlüözü GES & 1 & 0.023 \\
\hline 289439 & 4398035 & "GES3 & 0.97 & 0.022 \\
\hline 281606 & 4410076 & Tepebaşı Belediyesi GES & 0.097 & 0.002 \\
\hline 346669 & 4420766 & Beylikova Belediyesi GES & 0.071 & 0.002 \\
\hline
\end{tabular}

Not: Yukarıdaki tabloda isimleri verilen bazı tesislerin özel firmalara ait olması sebebiyle ismi açılanmayıp * ile gösterilmiştir. 

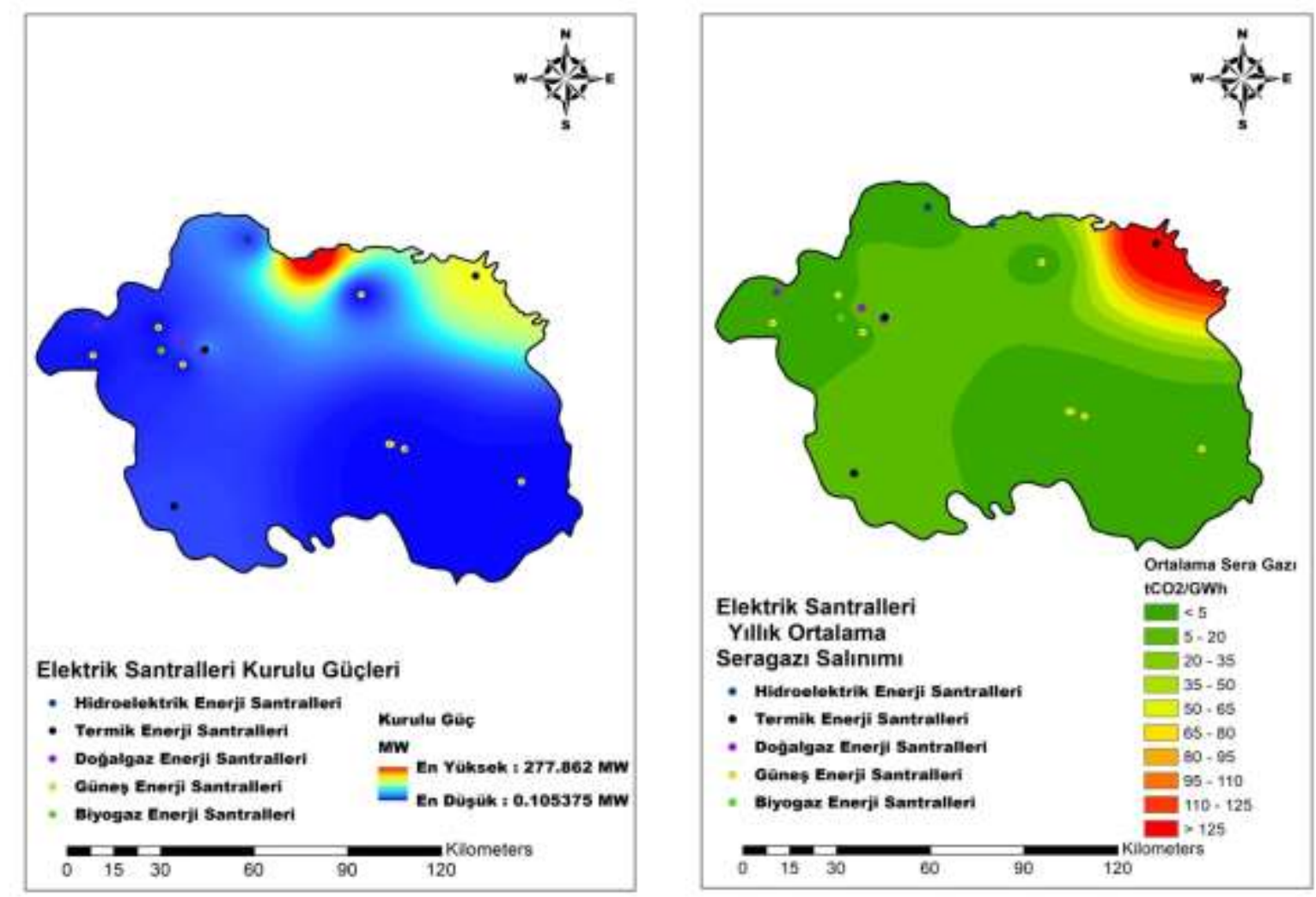

Şekil 4. a) Eskişehir ili elektrik santrallerin kurulu güçleri (MW) b) Eskişehir ili elektrik santrallerinin yıllık ortalama sera gazı salınımları $\left(\mathrm{tCO}_{2} / \mathrm{GWh}\right)$

Y1llı ortalama toplam sera gazı salınımlarının sadece \%3.28'i yenilenebilir enerji kaynaklarından \%96.72'sinin ise yenilenemeyen enerji kaynaklarından olduğu göz önüne alındığında küresel ısınma ve hava kirliği problemlerinin ortaya çıkmasında Eskişehir'in de payı olduğu açıktır. Tükenebilir enerji kaynaklarında \%96.72'lik sera gazı salınım payı içerisinde termik santrallerin yeri \%89.91 ile ilk siradadır.

$\mathrm{Bu}$ çalışmada Eskişehir ilinde yıllardır taşkın, sulama ve içme-kullanma suyu olarak faydalanılan Porsuk barajının bir HES'e dönüştürülmesi sonucu beklenen kurulu güç ve sera gazı azaltımı incelenerek belli bir kurulu güçteki bir HES'in ne kadarlık bir sera gazı salınımı azaltımı yapılacağı araştırılmıştır.

\subsection{Metot}

Eskişehir ilinde bulunan su kaynakları incelendiğinde birçok küçük ölçekli HES planlaması yapılabileceği görülmüştür. Bununla ilgili yapılan bir çalışmada toplam $6.30 \mathrm{MW}$ kurulu güçte bir planlama yapılabileceğini ortaya koyulmuştur [12]. Bölgedeki en büyük ve en önemli barajlardan birisi Porsuk barajıdır. Barajın konumu Şekil 5'te verilmiştir. Porsuk baraj1 1972 yılından beri bölgede taşkın, sulama ve içme-kullanma suyu amaçlı çalışan bir barajdır. Bu barajdan elde edilecek elektrik enerjisi ve barajın toplam kurulu gücü bu çalışma kapsamında diğer çalışmalardan farklı olarak sera gazı azaltımı açısında da değerlendirilmektedir. Bu amaç için SIMAHPP 5 Professional paket programı kullanılmışıı [13].

SIMAHPP5 Professional, hidrolik, finansal ve çevresel parametreleri kullanarak hidroelektrik enerji santrali projelerinin simülasyonu ve değerlendirmesini yapmak için kullanılan bir ön fizibilite analiz programıdır. Yazılım Windows işletim sistemi tabanlı özel bir şirkete ait bir programdır. SIMAHPP 5, uluslararası alanda danışmanlar, araştırmacılar ve türbin üreticileri tarafindan kabul görmüş ve sıklıkla kullanılan profesyonel bir yazılımdır. 


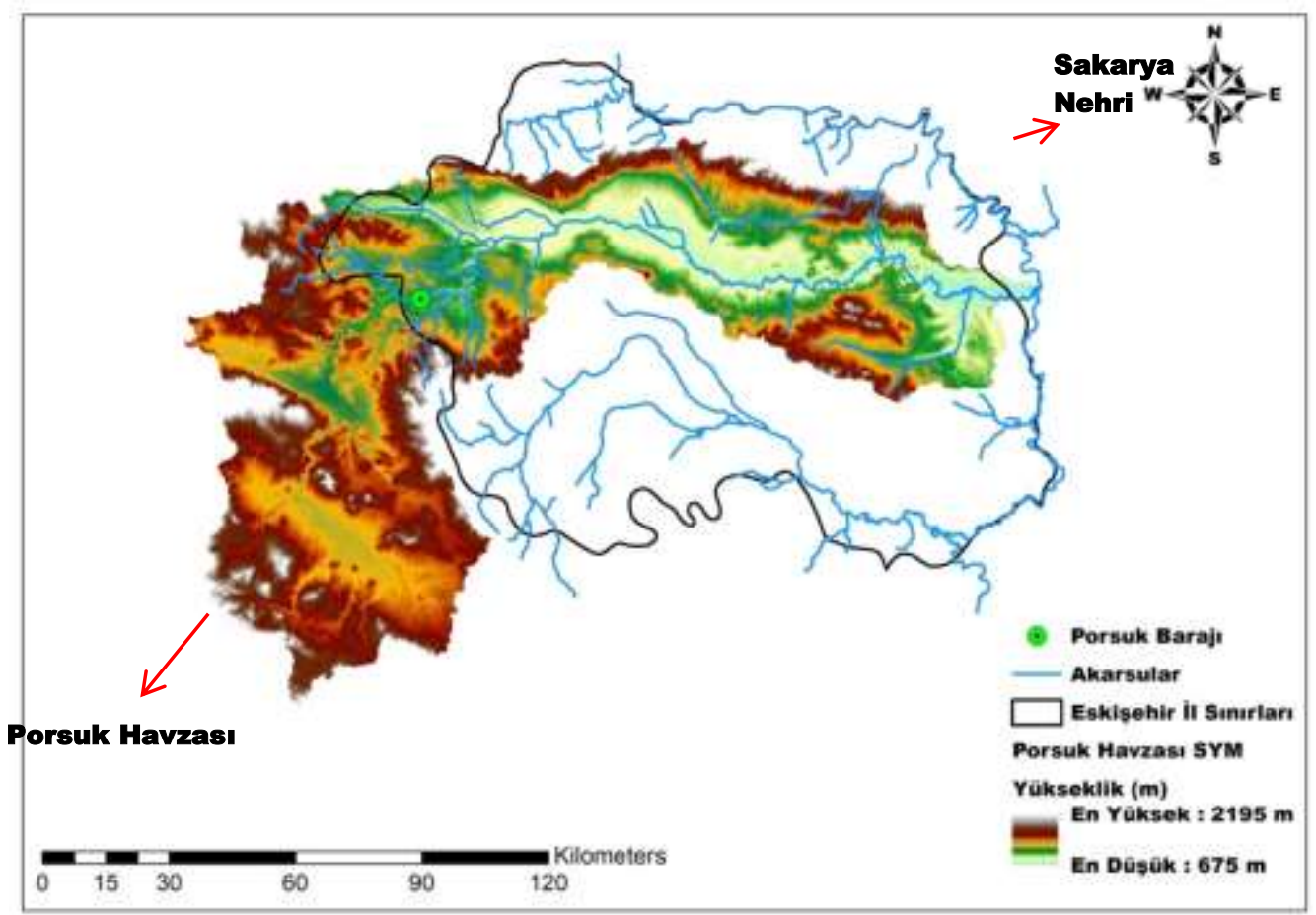

Şekil 5. Porsuk barajının il sınırlarındaki konumu

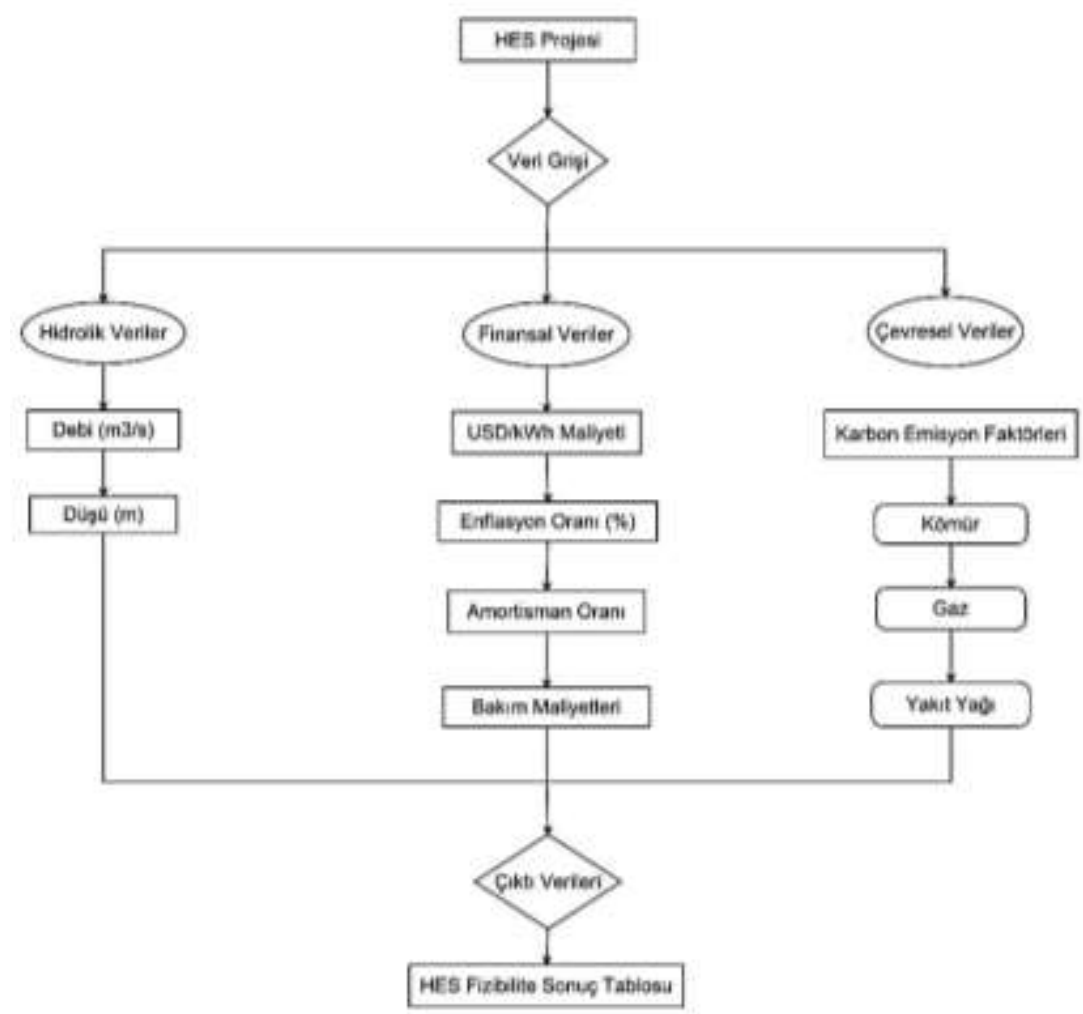

Şekil 6. SIMAHPP 5 Professional akış diyagramı [14]

SIMAHPP Professional, dizayn akışını belirlemek ve uygun hidro türbinleri seçmek, yıllık enerji üretimini en üst düzeye çıkarmak, enerji gelirini belirlemek, yatırım ve bakım maliyetlerini tahmin etmek, amortisman oranlarını belirlemek, bir yıl içinde çalışma süresini optimize etmek, Net Bugünkü Değer (NPV), İç Verim Oranı (IRR), geri ödeme süreleri ve projenin karbon emisyonunun azaltılmasının yanı sıra planlanan hidroelektrik projesi faaliyete geçecekse karbon piyasası geliri potansiyeli gibi bir çok yönü bulunan çok opsiyonlu bir simülatördür (www.hydroxpert.com). Yazılım, 
birden fazla Hidroelektrik santrali projesini analiz edebilecek kapasitededir. Yazılım analizlerini yapabilmesi için analiz, 3 farklı veri girişine ihtiyaç duymaktadır. Bu parametreler hidrolik, finansal ve çevresel parametrelerdir (Şekil 6). Yazılımda ilk veri girişi Hidrolik parametrelerdir. Bu parametreler baraj sahasına gelen günlük, aylık veya yıllık debi değerleri olarak girilebilmektedir. Yazılıma günlük debi değeri girilecekse, 365 değer, aylık debi değerleri girilecekse, 12 debi değeri, yıllık debi değeri girilecekse sadece 1 debi değeri girilmesi yeterlidir. Bu çalışmada Porsuk barajına gelen aylık ortalama debiler hidrolik parametre olarak girilmiştir (Şekil 7). Literatürde, hidroelektrik enerji hesaplarında, kurulu güç için $\mathrm{Q}_{50}$ ve maksimum tasarım debisi $\mathrm{Q}_{15}$ olarak verilmiştir. Başlangıç tasarım debisi, zamanın \%15-\%30'a karşı gelen değer olarak alınabileceği ifade edilmektedir [15-17]. Bu çalışmada dizayn debisi $12.19 \mathrm{~m}^{3} / \mathrm{s}$ olarak belirlenmiştir.
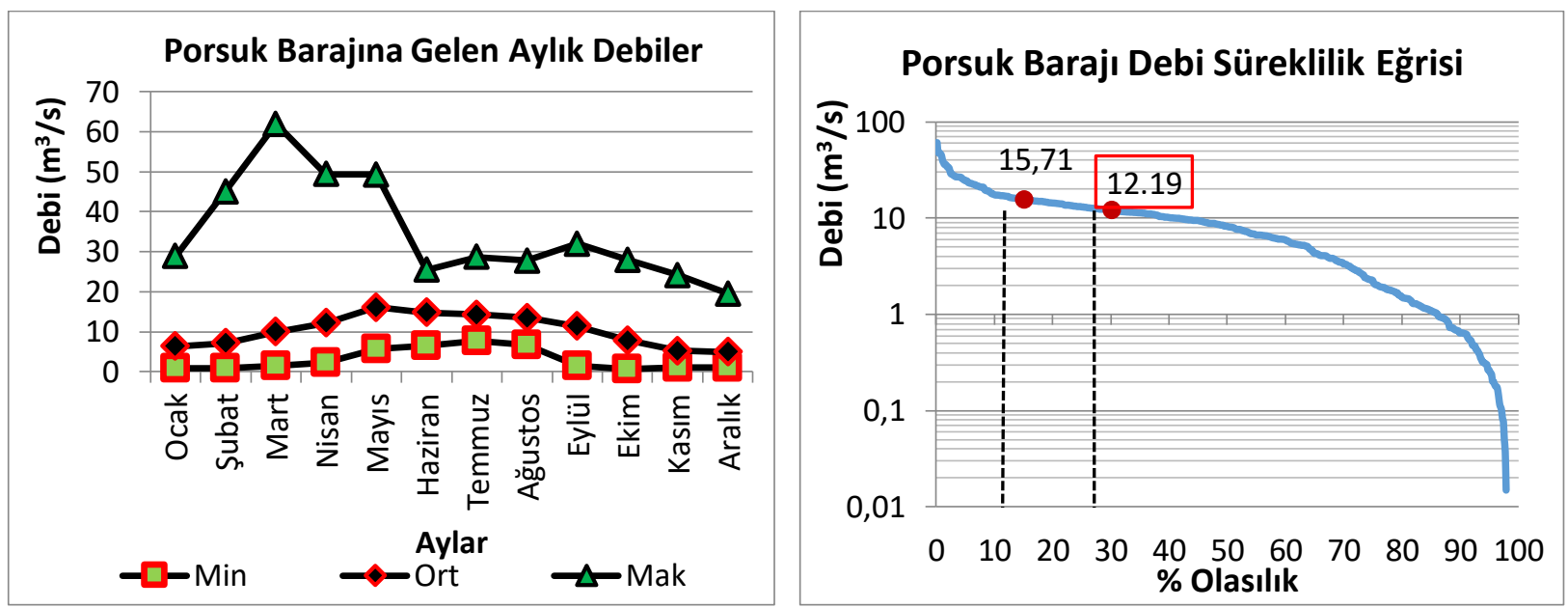

Şekil 7. Porsuk barajina gelen aylık ortalama debiler

Ayrıca bu bölümde suyun düşeceği net yükseklik Porsuk barajı için 40 metre olarak girilmiştir. SIMAHPP 5 programının hidroelektrik güç üretimi Denklem 1'de verilen formül kullanılarak hesaplanmıştır.

$$
\boldsymbol{P}=\boldsymbol{\eta} * \boldsymbol{g} * \boldsymbol{Q} * \boldsymbol{H}_{\boldsymbol{n e t}}
$$

Burada;

$\boldsymbol{P}$ : Hidroelektrik güç üretimi $(\mathrm{kW})$

$\boldsymbol{\eta}$ : Toplam verim katsayısı (\%90)

$\boldsymbol{g}$ : Yer çekimi ivmesi $\left(9.81 \mathrm{~m} / \mathrm{s}^{2}\right)$

$\boldsymbol{Q}$ : Dizayn debisi $\left(\mathrm{m}^{3} / \mathrm{s}\right)$

$\boldsymbol{H}_{\text {net }}$ : Net düşü yüksekliği (yersel ve sürekli enerji kayıpları ihmal edilmiştir)

Yazılıma ikinci veri girişi olarak finansal parametreler girilir. Bu bölümde kWh başına yatırım maliyetleri, yıllık veya aylık amortisman planı gibi veriler girilmektedir. Bu baraj Türkiye'de bulunduğu için ülkenin finansal parametreleri göz önünde bulundurularak değerler girilmiştir [18]. Son olarak, çevresel parametreler bölümünde karbon emisyonu Hidroelektrik enerji için diğer kaynaklara kıyasla karbon emisyonu azaltma potansiyelinin hesaplanması için oranlar girilmiştir. Bu oranlar doğal gaz için $0.5 \mathrm{kgCO}_{2} / \mathrm{kWh}$, kömür için $0.9 \mathrm{kgCO}_{2} / \mathrm{kWh}$, petrol için $0.65 \mathrm{kgCO}_{2} / \mathrm{kWh}$ olarak yazılıma girilmiştir [19]. $\mathrm{Bu}$ veriler girildikten sonra analiz tamamlanır.

\section{Bulgular ve Tartışma}

Bu çalışmada, Porsuk barajının HES'e dönüştürülmesi durumunda üreteceği enerji SIMAHPP 5 Professional yazılımı ile analiz edilerek karbon emisyon salınımına etkisi araştırılmıştır. Porsuk barajının yıllık üreteceği elektrik miktarı, kurulu güç, türbin tasarım akışı, enerji üretimi, enerji üretimi, 
yatırım ve geri ödeme süresi gibi hesaplanan veriler Tablo 2.'de verilmiştir. Ortaya çıkan sonuçlarda Porsuk barajının toplam yatırım maliyeti $11.81 \times 10^{6}$ USD olduğu tahmin edilmiştir. Ayrıca 12.19 $\mathrm{m}^{3} / \mathrm{s}^{\prime}$ lik bir dizayn debisinde 4.31 MW kurulu güce sahip olacağı bulunmuştur. Bu değer Porsuk HES projesi için DSİ planlamalarında yer alan 4.61 MW kurulu güce yakın çıktığı görülmüştür. Barajın yıllık enerji getirisi $1.024 \times 10^{6}$ USD olduğundan kendi maliyetini geri ödeme süresi barajların uzun ekonomik ömürlerinin yanında 14 yıl gibi kısa bir süre olarak ortaya çıkmıştır.

Tablo 2. SIMAHPP 5 Professional yazılımına göre Porsuk Hidroelektrik Santralinin proje karakteristikleri

\begin{tabular}{cc}
\hline Project karakteristikleri & Porsuk HES \\
Net düşü (m) & 40.000 \\
Dizayn debisi (m³/s) & 12.19 \\
Tasarım çalışma süresi (\%) & 40 \\
Güç üretimi (kW) & $4,305.020$ \\
Enerji üretimi (kWh/year) & $597,853,969.200$ \\
Enerji geliri (USD/year) & $1,024,739.96$ \\
Emisyon azaltımı (tCO2/year-Coal) & $\mathbf{9 , 0 5 0 . 8 7 4}$ \\
Emisyon azaltımı (tCO2/year-Gas) & $\mathbf{3 , 0 1 6 . 9 5 8}$ \\
Emisyon azaltımı (tCO2/year-Fuel) & $\mathbf{4 , 8 2 7 . 1 3 3}$ \\
Ortalama Karbon piyasa değeri (USD/year) & $34,146.614$ \\
Yatırım maliyeti (USD) & $11,814,170.51$ \\
$\mathrm{~kW}$ başına yatırım maliyeti (USD/kW) & $2,744.277$ \\
$\mathrm{kWh}$ başına yatırım maliyeti (USD/kWh) & 0.784 \\
Bakım ve işletme giderleri (USD/year) & $141,770.046$ \\
Net bugünkü değer (USD) & $1,105,535.764$ \\
İç verim oranı (\%) & 6 \\
Geri ödeme süresi (years) & 14 \\
Amortisman planı (yearly) & $80,757.795$ \\
Önerilen türbin tipi & Francis \\
Kur oranı (17.02.2020) 1 EUR/USD & 1.11 \\
\hline
\end{tabular}

Türkiye'nin 1990 yılından bu yana karbon emisyonlarını \%110 oranında arttırdığ1 belirtilmektedir [20]. Birleşmiş Milletlere sunulan raporda bu artışın hızlanarak devam etmesi öngörülmektedir [21]. Ancak Türkiye ve Sabancı Üniversitesi İstanbul Politikalar Merkezinin hazırladığı raporda ülkemizin ekonomik büyümeyi sürdürerek karbon emisyonlarını azaltabileceği belirtilmiştir [22]. Bu bağlamda hidrolik enerji gibi yenilenebilir enerji kaynaklarından yararlanarak hem ekonomik büyüme sürdürülebilir hem de karbon emisyonu azaltılabilir. Bu nedenle burada yapılan çalışmada ele alındığı gibi hidroelektrik enerji santrallerinin enerji ve ekonomi politikalarına $\mathrm{Bu}$ çalışmada yapılan analizler sonucunda yıllık $597 \mathrm{GWh}$ 'lık bir enerji üretiminin termik santraller yerine bir hidroelektrik enerji santralinden üretilmesi durumunda ne kadarlık bir emisyon azaltımı yapacağı ortaya konulmuştur. Aynı miktarda enerji üretimi için çalışmada incelenen Porsuk barajı kömür yakıtlı santrallere göre 9,050.874 $\mathrm{tCO}_{2} / \mathrm{y} 1$ l, doğalgaz yakıtl1 santrallere göre 3,016.958 $\mathrm{tCO}_{2} / \mathrm{y} 1$, petrol yakıtlı santrallere göre ise 4,827.133 $\mathrm{tCO}_{2} /$ yıl emisyon azaltımı yaptığı görülmektedir (Tablo 2). Türkiye dünya karbon piyasalarında yer almamasına rağmen içerisinde oluşturmuş olduğu gönüllü karbon piyasalarında 2011 y1lı itibariyle 95 milyon ton $\mathrm{CO}_{2}$ hacminin değeri 576 milyon dolar olarak belirtilmektedir [23]. Türkiye'de gönüllü karbon piyasalarında geliştirilen projeler ve emisyon azaltımları incelendiğinde 2018 yılına kadar 159 hidroelektrik projesinden 8,747,634 ton $\mathrm{CO}_{2} / \mathrm{y} 11$ sera gazı azaltımı olmuştur [24]. Bu çalışmada Porsuk barajından sağlanan emisyon azaltımının gönüllü karbon piyasasındaki ortalama değeri 34,146 USD/y1l olacaktır. Bu durum sürdürülebilir ekonomi ve çevre politikaları açısından ülkemize değer kazandıracaktır.

\section{Sonuç ve Öneriler}

Bu çalışmada, Türkiye'de son yıllarda yerli turizmin gözde şehirlerinden olan Eskişehir ilinin elektrik enerji santrallerinin durumu ortaya konmuştur. Yapılan araştırmada mevcut durumda Eskişehir ilinde 
toplam 558 MW kurulu gücün \%54.61'ini yenilenebilir enerji kaynakları, \%45.39'unu ise tükenebilir enerji kaynakları oluşturmaktadır. Buna rağmen yıllık ortalama sera gazı salınımlarının sadece \%3.28'i yenilenebilir enerji kaynakları kullanımından geri kalanı ise yenilemeyen enerji kaynakları kullanımından kaynaklandığı görülmüştür. Bu durum yenilenebilir enerji kaynaklarının özellikle çevreci yönüyle öne çıktığı sonucunu getirmektedir. Yenilenebilir enerji kaynaklarının en önemlilerinden biri de hidroelektrik enerji santralleridir. Çalışmada, araştırma yapısı olarak seçilen Porsuk barajının hidroelektrik enerji üretiminin yanı sıra karbon emisyonu azaltımına etkisi detaylı olarak incelenmiştir. SIMAHPP 5 Professional yazılımı yardımıyla yapılan analizlerde 4.31 MW'lık bir kurulu güce sahip Porsuk barajının ürettiği enerjinin kömür, gaz ve petrol gibi fosil kaynakları kullanan bir termik santralden üretilmesi durumunda ortalama 5,5631.55 $\mathrm{tCO}_{2} /$ y1l karbon emisyonu azaltımı sağlayacağ 1 görülmüştür. Ayrıca çalışmanın ekonomik boyutu değerlendirildiğinde barajdan üretilen enerjinin sağladığı karbon salınımı azaltımından 34,146 USD/yıl değerinde bir karbon piyasa değeri olacaktır. Böylelikle bu çalışmayla birlikte hidroelektrik santrallerin termik santrallere kıyasla küresel ısınmanın önlenmesi konusunda çevreye ve ülke ekonomisine yaptığı katkı tartışmasız bir şekilde ortaya konulmuştur.

\section{Yazarların Katkısı}

Bu makaledeki tüm katkı yazara aittir.

\section{Çıkar Çatışması Beyanı}

Yazarlar arasında herhangi bir çıkar çatışması bulunmamaktadır.

\section{Araştırma ve Yayın Etiği Beyanı}

Yapılan çalışmada araştırma ve yayın etiğine uyulmuştur.

\section{Kaynaklar}

[1] Bayraç H.N. 2009. Küresel Enerji Politikaları ve Türkiye: Petrol ve Doğalgaz Kaynakları Açısından Bir Karşılaştırma. Eskisehir Osmangazi University, Journal of Social Sciences, 10 (1): $116-142$.

[2] ExxonMobil. 2019. Outlook for Energy: A Perspective to 2040.

[3] Liu F., Duncan B.N., Krotkov N.A., Lamsal L.N., Beirle S., Griffin D., McLinden C.A., Goldberg D.L., Lu Z. 2019. A methodology 1 to constrain carbon dioxide emissions from coal-fired power plants using satellite observations of co-emitted nitrogen dioxide. Atmospheric Chemistry and Physics: Discussions., https://doi.org/10.5194/acp-2019-521.

[4] Gai Z., Zhao J., Zhang G. 2018. Typical calculation and analysis of carbon emissions in thermal power plants. IOP Conf. Series: Earth and Environmental Science, 128 (2018): 012176.

[5] Mozazzem S., Rasul M.G., Khan M.M.K. 2012. A Review on Technologies for Reducing $\mathrm{CO}_{2}$ Emission from Coal Fired Power Plants. Thermal Power Plants Book. Intechopen, DOI: $10.5772 / 31876$.

[6] WCA (World Coal Association). 2020. Coal's role in the electricity generation worldwide. (Erişim Tarihi: 11.02.2020).

[7] ALA (American Lung Association). 2011. Toxic Air: The Case for Cleaning Up Coal-Fired Power Plants. Report.

[8] Janssens-Maenhout G., Crippa M., Guizzardi D., Muntean M., Schaaf E., Dentener F., Bergamaschi P., Pagliari V., Olivier J.G.J., Peters J.A.H.W., van Aardenne J.A., Monni S., Doering U., Petrescu A.M.R. 2017. EDGAR v4.3.2 global atlas of the three major greenhouse gas emissions for the period 1970-2012. Earth Syst. Sci. Data Discuss., doi: 10.5194/essd-201779.

[9] Shindell D., Faluvegi G. 2010. The net climate impact of coal-fired power plant emissions. Atmos. Chem. Phys., 10, 3247-3260. 
[10] International Hydropower Association (IHA). 2019. Hydropower Status Report: Sector Trends and Insights, https://www.hydropower.org/download/file/nojs/21571. (Erişim Tarihi: 20.02.2020).

[11] Enerji Atlası. 2020. Eskişehir Elektrik Santralleri. https://www.enerjiatlasi.com/sehir/eskisehir/ (Erişim Tarihi: 15.02.2020).

[12] Bakış R., Bilgin M., Tuncan A., Altan M. 2009. Porsuk Havzasındaki Çok Amaçlı Barajlardan Elekrik Üretiminin Araştırılması. Eskişehir Osmangazi Üniversitesi Mühendislik Mimarlık Fakültesi Dergisi. XXII: 2.

[13] Hydro Xpert Technology. 2019. SIMAHPP 5 Professional- Windows Based Software.

[14] Koç C., Bayazıt Y., Bakış R. 2016. A Study on Determining the Hydropower Potential of Çine Dam in Turkey. Computational Water, Energy, and Environmental Engineering, 5: 79-85.

[15] Bayazıt M. 1985. Hidroloji, ITU, İstanbul.

[16] Yanmaz A.M. 2006. Applied Water Resources Engineering. METU, Ankara, 1-606.

[17] Gupta R.S. 2001. Hydrology and Hydraulic Systems. Second Edition, University, Bristol, 1- 867.

[18] EPİAŞ, 2020. Genel Raporlar, Enerji Piyasaları İşletme A.Ş. (Erişim Tarihi: 16.01.2020).

[19] Parliamentary Office of Science and Technology (POST) 2019. Carbon footprint of electricity generation, 268. https://www.parliament.uk/documents/post/postpn268.pdf (Erişim Tarihi: 20.07.2019).

[20] INDC. 2020. Intended Nationally Determined Contributions, United Nations Convention on Climate Change. https://unfccc.int/process-and-meetings/the-paris-agreement/nationallydetermined-contributions-ndcs/nationally-determined-contributions-ndes (Erişim Tarihi: 27.01.2021).

[21] WWF. 2020. Türkiye Sera Gazı Emisyonlarını Azaltarak da Büyümeye Devam Edebilir, https://www.wwf.org.tr/?4620 (Erişim Tarihi: 27.01.2020).

[22] WWF-IPM. 2015. Türkiye için Düşük Karbonlu Kalkınma Yolları ve Öncelikleri. Rapor, İstanbul.

http://awsassets.wwftr.panda.org/downloads/20151007_turkiye_icin_duuk_karbonlu_kalknma_ yollar_ve_oncelikleri_rapor.pdf (Erişim tarihi: 27.01.2021).

[23] Republic of Turkey: Ministry of Environment and Urban. 2012. Carbon Markets in Turkey. http://www.yegm.gov.tr/iklim_deg/document/karbon_piyasasi.pdf (Erişim Tarihi: 16.01.2020)

[24] Gurbuz C., Karatas O.N., Bekci I. 2019. A Research on Carbon Trade and Carbon Accounting Applications in the World and Turkey. Mehmet Akif Ersoy Journal of Social Sciences Institute, 11 (28): 424-438. 